\title{
THE ENZYMATIC CONVERSION OF MANDELIC ACID TO BENZOIC ACID
}

\author{
III. Fractionation and Properties of the Soluble Enzymes ${ }^{1}$ \\ C. F. GUNSALUS, R. Y. STANIER,2 and I. C. GUNSALUS \\ Laboratory of Bacteriology, University of Illinois, Urbana, Illinois
}

Received for publication May 27, 1953

The soluble protein fraction prepared from mandelate grown cells of Pseudomonas fluorescens as described in a previous paper (Gunsalus et al., 1953) contains four enzymes which are involved in the conversion of DL-mandelic acid to benzoic acid. These are: mandelic acid racemase, benzoylformic carboxylase, and two benzaldehyde dehydrogenases, linked respectively to diphosphopyridine nucleotide (DPN) and triphosphopyridine nucleotide (TPN). This paper describes the separation of these four enzyme activities and some of their properties.

\section{METHODS}

Assays. Benzoylformic carboxylase was assayed manometrically by measuring the rate of carbon dioxide evolution from benzoylformic acid at $\mathrm{pH}$ 6.0 and $30 \mathrm{C}$. The test system contained 100 $\mu \mathrm{g}$ of cocarboxylase, $50 \mu \mathrm{M}$ of sodium benzoylformate, and phosphate buffer $(0.1 \mathrm{M}, \mathrm{pH} 6.0)$ sufficient to give a total volume of $2.5 \mathrm{ml}$. Measurements were usually made in air, but crude extracts still containing the particle fraction were assayed in nitrogen to preclude oxidation of the benzaldehyde formed. The rate of decarboxylation is a linear function of enzyme concentration over the measurable range. The unit of activity is defined as the amount of enzyme which decarboxylates one micromole of benzoylformic acid per hour under the specified conditions.

Mandelic acid racemase was assayed by an indirect manometric method, that is, by determining the rate of oxygen uptake by washed particles $(L(+)$-mandelate dehydrogenase) with D-mandelic acid as substrate in the presence of

1 This work was supported in part by grants from the Office of Naval Research and the Atomic Energy Commission.

2 Fellow of the J. S. Guggenheim Memorial Foundation, 1951-1952. Present address: Department of Bacteriology, University of California, Berkeley 4, California. the racemase. Since the washed particles do not oxidize the $D$-isomer, the rate of oxygen uptake in the assay reflects the rate of conversion of D-mandelic acid to the I-isomer. Each assay vessel contained, in the main compartment, enough washed particles to oxidize $30 \mu \mathrm{M}$ of sodium L-mandelate per hour, plus appropriate dilutions of the racemase, with sufficient $0.1 \mathrm{M}$ phosphate buffer ( $\mathrm{pH} 7.0)$ to give a total cup volume of $2.5 \mathrm{ml}$. The center well contained $\mathrm{KOH}$, and the substrate (30 $\mu \mathrm{M}$ of $\mathrm{Na} \mathrm{D}$-mandelate) was placed in a side arm. There is a marked initial lag in oxygen uptake (caused by initial absence of an oxidizable substrate); thus for assay, oxidation rates were calculated after the oxygen uptake became linear-between 5 and 25 minutes after tipping the substrate. The unit of activity is defined as the amount of enzyme necessary to cause oxidation of $15 \mu \mathrm{M}$ of D-mandelic acid per hour under the specified conditions, i.e., that amount of racemase which produces I-mandelic acid at a rate which half-saturates the L-mandelic dehydrogenase. The range over which rate of oxygen uptake is a linear function of racemase concentration is narrow, and the method has a probable accuracy not greater than \pm 20 per cent.

The benzaldehyde dehydrogenases were assayed by measuring the rate of reduction of the respective pyridine nucleotides. Each test system contained $2 \mu \mathrm{M}$ of benzaldehyde, 200 to $300 \mu \mathrm{g}$ $0.3 \mu \mathrm{M}$ ca of either diphosphopyridine nucleotide or triphosphopyridine nucleotide, the enzyme fraction under test, and $0.3 \mathrm{ml} \mathrm{M}$ phosphate buffer ( $\mathrm{pH} \mathrm{8.5)}$ in a total volume of $3 \mathrm{ml}$. The optical density at $340 \mathrm{~m} \mu$ was measured at intervals of 15 seconds for a period of 5 minutes, using the Beckman model DU spectrophotometer, at room temperature. The rate of increase of optical density is a linear function of the concentration of enzyme over the measurable range. The unit of activity is the amount of enzyme which causes a change of 0.01 unit in optical 
density per minute under the specified conditions. On occasion, tests were run with a total volume of $0.5 \mathrm{ml}$, the system being scaled down proportionately.

Removal of nucleic acid. The soluble protein fraction was obtained from sonic extracts (after high-speed centrifugation to remove the coarse particles) by precipitation between 0.33 and 0.67 saturation with ammonium sulfate. This fraction contains approximately 20 per cent nucleic acids as measured by the spectrophotometric method of Warburg and Christian (1941). Before further fractionation, most of the nucleic acid was removed by treatment with protamine sulfate. The $\mathrm{pH}$ of the enzyme solution was adjusted to 6.0 to 6.3 with $0.1 \mathrm{~N}$ acetic acid, and a solution of protamine sulfate $(20 \mathrm{mg}$ per $\mathrm{ml}, \mathrm{pH} 5.0$ ) was added slowly in a fine stream to the ice-cooled solution with vigorous mechanical agitation. The precipitate was removed periodically by centrifugation, and the nucleic acid content of the supernate estimated spectrophotometrically. By cautious successive additions of protamine sulfate, the nucleic acid content can be reduced to about 1 per cent (ratio O.D. $280 / 260=1.30$ ) with only slight losses of the enzymatic activities. Approximately 0.1 volume of protamine sulfate is required with extracts which contain 8 to 12 $\mathrm{mg}$ of protein per $\mathrm{ml}$.

\section{RESULTS}

Isolation and properties of benzoylformic carboxylase. Benzoylformic carboxylase, a relatively stable enzyme, was obtained free of mandelic acid racemase and of the triphosphopyridine nucleotide linked benzaldehyde dehydrogenase by two successive ammonium sulfate fractionations of the protamine treated extract, followed by brief heating ( $50 \mathrm{C}$ for 45 seconds). As shown in table 1,17 per cent of the activity originally present in the soluble protein fraction was recovered, and a 7-fold purification achieved. The final fraction still contained a small amount of the diphosphopyridine nucleotide linked benzaldehyde dehydrogenase.

The purified enzyme was about 20 per cent resolved with respect to cocarboxylase. Complete resolution with negligible loss of activity was obtained by dialysis in the cold for 24 hours against 0.02 м sodium pyrophosphate ( $\mathrm{pH} 8.5$ ), followed by dialysis against distilled water for 12 hours. The Michaelis constant for cocarboxyl- ase saturation of the benzoylformic carboxylase approximates $4 \times 10^{-6}$ moles per liter. No stimulation of activity by $\mathrm{Mg}^{++}$was shown at any stage of purification.

The purified enzyme does not decarboxylate pyruvic, $\alpha$-ketobutyric, or $\alpha$-ketoglutaric acids at appreciable rates (i.e., less than 5 per cent of the rate with benzoylformic acid). Gunter's (1951) experiments on the enzymatic degradation of $p$-hydroxymandelic acid suggest that benzoylformic carboxylase can also decarboxylate $p$-hydroxybenzoylformic acid, but this compound was not available to use for a direct test. The substrate

TABLE 1

Partial purification of benzoylformic carboxylase

\begin{tabular}{|c|c|c|c|}
\hline FRACTION & $\underset{\text { ACTIVITY }}{\text { TOTAL }}$ & REcov- & $\underset{\text { (PROTIIN) }}{Q_{\mathrm{CO}_{2}}}$ \\
\hline & units* & $\%$ & \\
\hline $\begin{array}{l}\text { (1) Soluble protein frac- } \\
\text { tion }\end{array}$ & 110,000 & 100 & 930 \\
\hline $\begin{array}{l}\text { (2) (1) protamine } \\
\text { treated } f\end{array}$ & 84,000 & 77 & 1,580 \\
\hline $\begin{array}{l}\text { (3) (2) ppt 0.4-0.7 Sat. } \\
\left(\mathrm{NH}_{4}\right)_{2} \mathrm{SO}_{4}\end{array}$ & 62,000 & 56 & 3,650 \\
\hline $\begin{array}{l}\text { (4) (3) ppt 0.5-0.7 Sat. } \\
\left(\mathrm{NH}_{4}\right)_{2} \mathrm{SO}_{4}\end{array}$ & 20,000 & 18 & 5,650 \\
\hline $\begin{array}{l}\text { (5) (4) heated, } 50 \mathrm{C}, 45 \\
\text { min }\end{array}$ & 19,000 & 17 & 6,100 \\
\hline
\end{tabular}

* One unit $=1 \mu \mathrm{M} \mathrm{CO}_{2}$ formed per hr at $30 \mathrm{C}$, $\mathrm{M} / 10 \mathrm{pH} 6$ phosphate, see text.

+ To $280 / 260$ ratio $=1$, see text.

affinity for benzoylformic acid is relatively high $\left(\mathrm{K}_{\mathrm{M}}=9 \times 10^{-4}\right)$. The optimal $\mathrm{pH}$ lies between 6.0 and 6.5 .

Demonstration of the mandelic acid racemase. As shown in an earlier paper (Stanier et al., 1953) washed particles from sonic extracts of mandelate grown cells oxidize only the L-isomer of mandelic acid, but addition of the soluble protein fraction to the washed particles permits oxidation of the D-isomer as well. The soluble protein fraction by itself cannot consume oxygen with either isomer. Since it has been shown also that the L-mandelate oxidizing activity of crude whole extracts can be recovered almost quantitatively in the particle fractions, the role of the soluble protein fraction in the oxidation of the D-isomer suggests two possible explanations: i.e., this fraction contains (a) a specific D-mandelic acid dehydrogenase, requiring the electron-trans- 


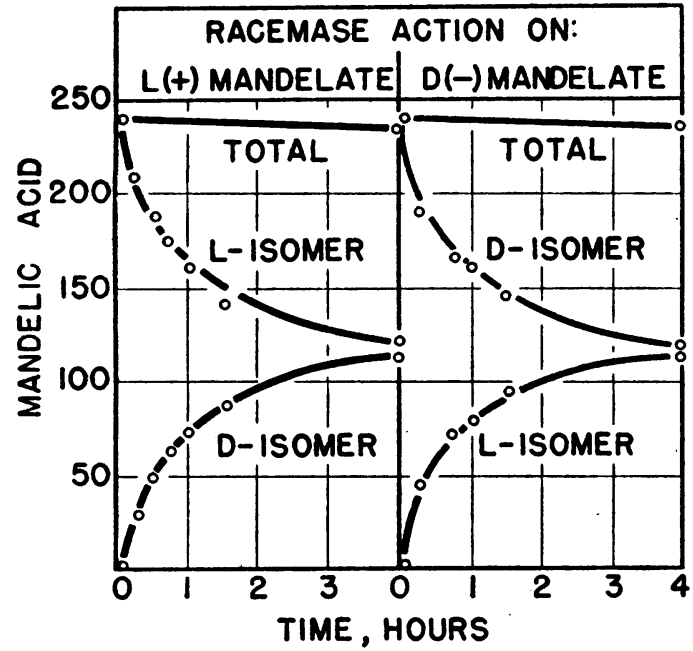

Figure 1. Racemization of $\mathrm{D}(-)$ and $\mathrm{L}(+)$ mandelic acid by soluble protein fraction. (See text for conditions.) were added to one tube, and the same amount of $0.1 \mathrm{M}$ sodium L-mandelate, to the other. Aliquots $(1.0 \mathrm{ml})$ were withdrawn at intervals, boiled to destroy the enzyme, and assayed for their content of the $D(-)$ and $I(+)$-mandelic acid. The assays were conducted in Warburg vessels which contained the sample under test in the main compartment, $0.2 \mathrm{ml}$ of $\mathrm{KOH}$ in the center well, $0.2 \mathrm{ml}$ of a suspension of washed particles in one side arm, and $0.2 \mathrm{ml}$ of soluble protein fraction in the second side arm. The washed particles were tipped first, and the total oxygen uptake determined; from this value the amount of L-isomer could be calculated. On subsequent tipping of the soluble protein fraction a second oxygen uptake occurred; from this the amount of D-isomer could be calculated. The results of this experiment, plotted in figure 1, show that the soluble protein fraction contains

TABLE 2

Separation of diphosphopyridine nucleotide (DPN) and triphosphopyridine nucleotide (TPN) linked benzaldehyde dehydrogenases

(1) Soluble protein after protamine

(2) (1) Precipitated with $\left(\mathrm{NH}_{4}\right)_{2} \mathrm{SO}_{4}$

(a) 0.33 to 0.5 Sat.

(b) 0.5 to 0.7 Sat.

(3) (2a) Reprecipitated with $\left(\mathrm{NH}_{4}\right)_{2} \mathrm{SO}_{4}$ $0.4-0.5$ Sat.

(4) (3) Aged 6 days

(5) (2b) Reprecipitated with $\left(\mathrm{NH}_{4}\right)_{2} \mathrm{SO}_{4}$ $0.5-0.6$ Sat.

(6) (5) Heated, 50 C, $45 \mathrm{~min}$

\begin{tabular}{|c|c|c|c|c|c|}
\hline \multirow{3}{*}{$\begin{array}{c}\text { PROTEN } \\
\text { mg } \\
243\end{array}$} & \multicolumn{2}{|c|}{ DPN LINEXD } & \multicolumn{2}{|c|}{ TPN LDVRed" } & \multirow{3}{*}{ 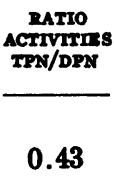 } \\
\hline & Unils & S.A. ${ }^{\dagger}$ & Unils & S.A.t & \\
\hline & 8,250 & 34 & 3,540 & 15 & \\
\hline 82 & 2,260 & 28 & 1,630 & 20 & 0.7 \\
\hline 77 & 4,600 & 60 & 306 & 4 & 0.07 \\
\hline 15 & 216 & 14 & 450 & 30 & 2.0 \\
\hline 15 & 0 & 0 & 260 & 17 & $\infty$ \\
\hline 15 & 396 & 26 & 43 & 3 & 0.12 \\
\hline 15 & 130 & 9 & 0 & - & o \\
\hline
\end{tabular}

* We wish to thank Dr. N. O. Kaplan for the triphosphopyridine nucleotide used in these experiments.

$\dagger$ Specific activity: units/mg protein.

porting system of the particles for connection to molecular oxygen, or (b) an enzyme catalyzing the conversion of either the $\mathrm{D}$ - or the L-isomer to a racemic mixture. In order to decide between these two possibilities, the following experiment was undertaken.

Two test tubes, each containing $1.0 \mathrm{ml}$ of a soluble protein fraction and $6.5 \mathrm{ml}$ of $0.1 \mathrm{M}$ phosphate buffer ( $\mathrm{pH} 7.0$ ), were placed in a water bath at $30 \mathrm{C}$. After thermal equilibration, $2.5 \mathrm{ml}$ of $0.1 \mathrm{M}$ sodium D-mandelate $(250 \mu \mathrm{M})$ an enzyme which converts either isomer of mandelic acid to a racemic mixture. Since the I-mandelate oxidizing activity of crude sonic extracts is virtually all recovered in the particle fractions, an explanation of the racemizing effect in terms of two sterically specific dehydrogenases is highly improbable. Data which will be published elsewhere suggest that the mechanism of the reaction is a direct interconversion of the D- and L-isomers, not involving benzoylformic acid as an intermediate. It is thus analo- 
gous to the interconversion of $\mathrm{D}$ - and I-alanine by alanine racemase (Wood and Gunsalus, 1951).

Preparations of the racemase free of benzoylformic carboxylase activity and containing negligible amounts of the benzaldehyde dehydrogenases were obtained as follows: (a) ammonium sulfate precipitation ( 0 to 0.33 saturation) of protamine treated soluble protein fraction, (b) heating to $50 \mathrm{C}$ for 5 minutes, and (c) dialysis against $0.02 \times$ sodium pyrophosphate ( $\mathrm{pH} 8.5$ ) for 12 hours, followed by dialysis against distilled water for a further 12 hours. The properties of the isolated enzyme have not yet been studied.

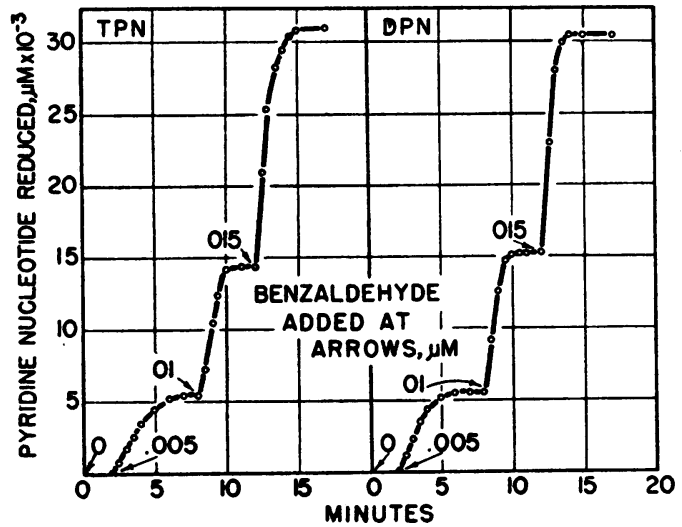

Figure 2. Pyridine nucleotide reduction as a function of the amount of benzaldehyde added. Conditions of experiment as outlined for enzyme assay (see text). The isolated diphosphopyridine nucleotide and triphosphopyridine nucleotide specific dehydrogenases were used (fractions 4 and 6 , table 2).

The inducible nature of the racemase. Existing data on the enzymatic patterns of living cells of $P$. fluorescens, strain A.3.12 (Stanier, 1947, 1948), shows that the oxidation of mandelic acid is substrate-activated, i.e., the L-mandelic acid dehydrogenase is an inducible (adaptive) enzyme. Unpublished experiments have shown further that cells grown on either L- or D-mandelate immediately oxidize both isomers at the same rate. In enzymatic terms, this could mean either that the racemase is a so-called "constitutive" enzyme, synthesized by the cells under all conditions of growth, or that its formation can be evoked by either isomer of mandelic acid. In order to distinguish between these two possibilities, the racemizing activities of sonic extracts prepared from cells grown in the presence and absence of mandelate were compared. For the cells grown without mandelate, 0.5 per cent yeast extract (Difco) served as an energy source. The cells were disrupted by sonic treatment as previously described, the coarse particle fractions removed by centrifugation for an hour at 22,000 $G$, and the supernates compared for their ability to activate the oxidation of D-mandelic acid by washed particles from mandelate grown cells. The extract from cells grown on yeast extract had a negligible racemizing activity (less than 10 per cent of that shown by the extract from mandelate grown cells). Hence formation of the racemase is substrate-activated; either isomer

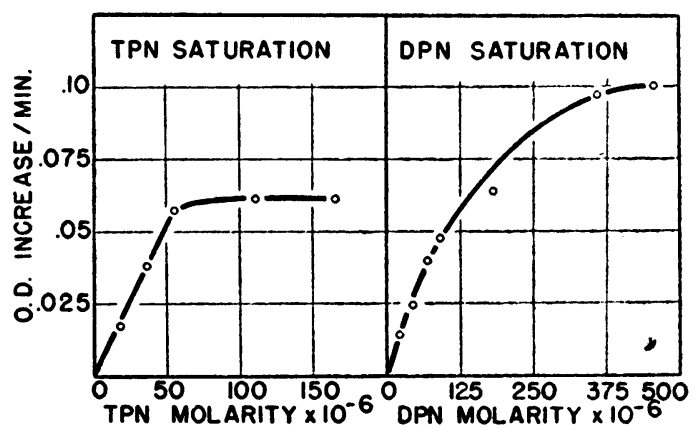

Figure 3. Pyridine nucleotide saturation curves for the diphosphopyridine nucleotide and triphosphopyridine nucleotide linked benzaldehyde dehydrogenases. Conditions for experiment as described for enzyme assay (see text). Each cuvette contained 6 units of the triphosphopyridine nucleotide linked enzyme or 10 units of the diphosphopyridine nucleotide linked enzyme.

can induce its formation even though it has a metabolic function only in the degradation of D-mandelic acid.

Separation of the two benzaldehyde dehydrogenases. The soluble protein fraction catalyzes the reduction of either diphosphopyridine nucleotide or triphosphopyridine nucleotide in the presence of benzaldehyde. Fractionation yielded two preparations, each of which was linked to only one of the pyridine nucleotides (table 2). Recoveries were extremely low, and no significant degree of purification was achieved with either enzyme.

The diphosphopyridine nucleotide and triphosphopyridine nucleotide are completely reduced by their respective dehydrogenases in the presence of excess benzaldehyde; with a limited quantity of benzaldehyde, an equimolar amount of pyridine nucleotide is reduced. Thus, both 
dehydrogenases catalyze essentially irreversible reactions. The proportionality between the amount of benzaldehyde added and the amount of pyridine nucleotide reduced is shown for each enzyme in figure 2. Saturation curves of the two dehydrogenases for their respective coenzymes are shown in figure 3. The diphosphopyridine nucleotide linked enzyme has a sharp and narrow $\mathrm{pH}$ optimum at 8.5, while the $\mathrm{pH}$ optimum of the triphosphopyridine nucleotide linked enzyme lies at 9.0 or above. Both dehydrogenases show a high degree of substrate specificity. The oxidation of acetaldehyde, glyceraldehyde, and methyl glyoxal as measured by diphosphopyridine nucleotide or triphosphopyridine nucleotide reduction is negligible even with crude fractions.

\section{DISCUSSION}

The initial steps in the metabolism of mandelic acid by $P$. fluorescens which were inferred from analyses of the enzymatic patterns of intact cells (Stanier, 1947, 1948) have been confirmed by the present enzymatic study. Mandelic acid is first dehydrogenated to benzoylformic acid by an enzyme specific for the $\mathrm{L}(+)$-isomer; benzoylformic acid is then decarboxylated to benzaldehyde which is in turn dehydrogenated to yield benzoic acid. The hitherto somewhat puzzling observation that intact cells invariably oxidize both isomers of mandelic acid at identical rates has been clarified by the discovery in extracts of a previously unsuspected racemase which catalyzes the interconversion of the two isomers. The racemase, like all other enzymes of the sequence, is substrate induced; but since either isomer can evoke racemase formation, its existence could not be detected by in vivo analyses of induced enzymatic patterns. From the metabolic standpoint, the racemase initiates the dissimilation of $D(-)$-mandelic acid. It plays no role in the dissimilation of the $L(+)$-isomer, which can be oxidized directly to benzoylformic acid by L-mandelic acid dehydrogenase. The induction of racemase formation by exposure of cells to the $L(+)$-mandelic acid is thus an interesting example of the synthesis of a physiologically nonfunctional enzyme.

The oxidation of L-mandelic acid to benzoylformic acid is mediated by an enzyme bound to a particulate fraction of the cell. The particles also contain dehydrogenases for succinic and malic acids, together with the complete system of enzymes required for the transport of electrons from these three substrates to molecular oxygen. So far, the L-mandelic acid dehydrogenase has not been separated from the other enzymes of the particle fraction, nor have any cofactor requirements for this system been demonstrated.

The decarboxylation of benzoylformic acid to benzaldehyde is brought about by a soluble carboxylase, requiring cocarboxylase for activity. This enzyme differs markedly from the carboxylases of yeast and green plants (Vennesland, 1951) both in its much greater substrate specificity and in its relatively high substrate affinity.

The dehydrogenation of benzaldehyde to benzoic acid is catalyzed by two soluble dehydrogenases which act, respectively, with diphosphopyridine nucleotide and triphosphopyridine nucleotide. The diphosphopyridine nucleotide linked dehydrogenase has been shown to transfer electrons from benzaldehyde to molecular oxygen via the transport system located in the particle fraction; but this connection is easily destroyed in vitro, which suggests the existence of a labile enzyme or cofactor functioning between reduced diphosphopyridine nucleotide and the cytochrome system of the particles. Whatever the nature of this labile link, it appears not to be required for the transport of electrons from mandelic acid to the cytochrome system, since preparations of the particles which readily consume oxygen when furnished with L-mandelic acid may be wholly devoid of the ability to couple benzaldehyde dehydrogenation to oxygen.

\section{SUMMART}

Four soluble enzymes concerned with the conversion of mandelic acid to benzoic acid have been found in extracts prepared from mandelate grown cells of the bacterium Pseudomonas fluorescens. They are: mandelic acid racemase, which converts either isomer to a racemic mixture; benzoylformic carboxylase, which catalyzes a decarboxylation of benzoylformic acid to benzaldehyde and requires cocarboxylase for its activity; and two benzaldehyde dehydrogenases, which react respectively with diphosphopyridine nucleotide (DPN) and triphosphopyridine nucleotide (TPN).

In the light of these and preceding findings, the conversion of mandelic acid to benzoic acid 
can be formulated as follows:

$$
\mathrm{D}(-) \text {-mandelic acid } \stackrel{\text { racemase }}{\longleftarrow} \mathrm{L}(+) \text {-mandelic acid } \stackrel{\text { dehydrogenase }}{\stackrel{-2 \mathrm{H}}{\longrightarrow}}
$$

benzoylformic acid $\underset{-\mathrm{CO}_{2}}{\stackrel{\text { carboxylase }}{\longrightarrow}}$ benzaldehyde

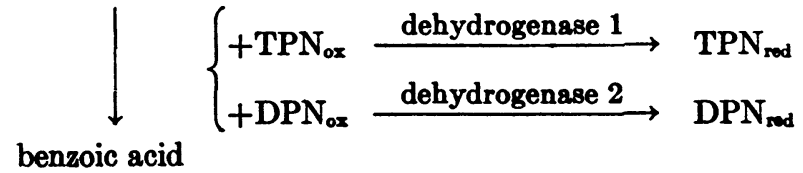

\section{REFERENCES}

Gunsalus, I. C., Gunsalus, C. F., and Stanier, R. Y. 1953 The enzymatic conversion of mandelic acid to benzoic acid. I. Gross fractionation of the system into soluble and particulate components. J. Bact., 66, 538542.

Gunter, S. 1951 Studies on enzymatic adaptation. Thesis, University of California, Berkeley, California.

Stanier, R. Y. 1947 Simultaneous adaptation: A new technique for the study of metabolic pathways. J. Bact., 54, 339-348.

Stanier, R. Y. 1948 The oxidation of aromatic compounds by fluorescent pseudomonads. J. Bact., 65, 477-493.

Stanier, R. Y., Gunsalus, I. C., and Gunsalus, C. F. 1953 The enzymatic conversion of mandelic acid to benzoic acid. II. Properties of the particulate fractions. J. Bact., $66,543-547$.

Vennesland, B. 1951 Keto acid decarboxylases. Enzymes, 2 (part 1), 183-215.

Warburg, O., and Christian, W. 1941 Isolierung und Krystallisation des Gaerungsferments Enolase. Biochem. Z., 310, 384-425.

Wood, W. A., and Gunsalud, I. C. 1951 Dalanine formation: A racemase in Streptococcus faecalis. J. Biol. Chem., 190, 403-415. 